\title{
Amsterdaml'og
}

\section{CBM Life Management and Case Study}

\author{
S. Jewell (Composite Energy Ltd.) and D. Sharples (Composite Energy Ltd.)
}

\section{SUMMARY}

Coal Bed Methane developments are characterised by a wide variety of technical solutions driven by geography as much as geology. The relatively immature state of the scientific understanding of CBM (compared with conventional oil and gas) is one of the reasons why many different solutions have been deployed when it comes to the development of reserves.

Most of the world's developed CBM reserves exist in North America with expanding development activity in Australia. In other parts of the world (China, India, Europe) exploitation of CBM is at a much earlier stage with the emphasis on the exploration and appraisal of prospects in known coal regions.

Composite Energy is a relatively new British CBM Company with licences currently across the UK and in eastern Poland. The approach adopted by Composite is to appraise known coal bearing areas with vertical boreholes to confirm coal volumes and gas content (the exploratory phase). In order to evaluate productivity where good development potential exists, Composite would implement a multi-well pilot development consisting of 4-6 wells relatively closely spaced. Coal deposits can exhibit considerable heterogeneity and the purpose of testing a number of wells together as a pilot can be summarised as follows:

1. A single well test may be misleading (good or bad) due to heterogeneous reservoir properties (permeability especially)

2. Desorption of gas is a function of average reservoir pressure and so true rates, reflecting more realistic development conditions, can only be achieved when individual well pressures begin to interfere with each other and significant average reservoir pressure declines are realised.

3. Multiple wells can provide much better insight into development costs and assist with completion optimisation

Composite will present the Airth Pilot Development in Scotland which consists of two vertical and six multi-lateral horizontal development wells. These wells are draining an area of some 6-10 sq.km. 3D reservoir simulation is being used to history match production performance to date and plans are in place to implement a 4MW power generation scheme to complete the pilot development. Gas sales under a full development of the acreage are expected to feed the existing UK gas transportation infrastructure directly. 